\title{
Metabolomic, Biochemical, and Gene Expression Analyses Reveal the Underlying Responses of Resistant and Susceptible Banana Species during Early Infection with Fusarium oxysporum f. sp. cubense
}

Wenbin Li, Chunqiang Li, Jianbo Sun, and Ming Peng, Key Laboratory of Biology and Genetic Resources of Tropical Crops, Institute of Tropical Bioscience and Biotechnology, Chinese Academy of Tropical Agricultural Sciences, Haikou, 571101, Hainan, China

\begin{abstract}
Banana (Musa spp.) is an important staple and economic fruit crop, especially in Africa, Southeast Asia, and Latin America. The wilt disease caused by Fusarium oxysporum f. sp. cubense, especially F. oxysporum f. sp. cubense strain TR4, is disastrous for banana production. Banana plants infected by F. oxysporum f. sp. cubense TR4 gradually die from leaf blight or vascular rot. There is no efficient method to control this disease, and the underlying response of banana plants to $F$. oxysporum $\mathrm{f}$. sp. cubense remains unknown. In this study, the responses of an economically important banana cultivar, the F. oxysporum f. sp. cubense-susceptible 'BX', and a wild banana relative, the $F$. oxysporum f. sp. cubense-resistant Musa yunnanensis ('YN'), to F. oxysporum $\mathrm{f}$. sp. cubense infection were investigated using metabolomic, biochemical, and molecular biological methods. Numerous metabolomic compounds, including defense-responsive signaling molecules, phytohormones, phenolics, and antioxidants, were identified through metabolomic

analysis. Changes in salicylic acid (SA), methyl-jasmonic acid, abscisic acid (ABA), cytokinin, 3-indoleacetic acid, gibberellic acid, and total phenolic levels were detected using liquid chromatography-mass spectrometry and the Folin-Ciocalteu method. The expression levels of genes involved in the biosynthesis of some defense-responsive compounds were studied through quantitative real-time polymerase chain reaction. The results revealed that the resistant $\mathrm{YN}$ had a larger change in SA content and a lower $\mathrm{ABA}$ level throughout the early infection period, compared with the levels in $B X$. The susceptible BX had a lower phenolic content. The resistant $Y N$ also expressed pathogenesis-related $(P R)$ genes, especially $P R 1, P R 4, P R 5-1$, and $P D F 2.2$, at higher levels than the susceptible BX. These dynamic metabolic and gene-expression profiles from susceptible and resistant banana during the early stage of $F$. oxysporum $\mathrm{f}$. sp. cubense infection increase our understanding of the complex interaction response between this crop and its pathogen.
\end{abstract}

Banana (Musa spp.) serves as a staple food, due to its high nutritional and carbohydrate contents, to people in areas such as Africa, Southeast Asia, and Latin America, and is a favored fruit around the world. According to Food and Agriculture Organization estimates, more than 100 million tons of banana fruit were produced worldwide in $2013,54.6 \%$ of which were in Asia (http://www.fao.org/faostat/en/\#data/QC/visualize). However, in recent decades, this crop has been seriously threatened by Fusarium wilt disease caused by the soilborne fungus Fusarium oxysporum f. sp. cubense. The virulent strain $F$. oxysporum f. sp. cubense tropical race 4 (TR4) is particularly lethal to the main commercial cultivar, 'Cavendish Brazilian' or 'BaXi' ('BX'), accounting for approximately $45 \%$ of all banana production in the world (Ploetz 2015). F. oxysporum f. sp. cubense TR4 causes substantial yield loss, because it usually breaks out during the fruiting period. It chokes the xylem vessels, eventually killing the plant. In addition, the fungus spreads rapidly from infected fields through rain, irrigation, and foot traffic. There is still no effective method to control this disease in infected banana fields (Ploetz 2006, 2015).

Recent research has shown that many wild banana relatives are highly resistant to TR4 (Chen et al. 2006; Huang et al. 2005; Li et al. 2015c). The wild species Musa yunnanensis ('YN') from Yunnan Province, China, can tolerate seasonal frosts (Häkkinen and Wang 2007) and exhibits more resistance in the field than in greenhouse conditions ( $\mathrm{Li}$ et al. 2015c). Wild resistant banana species are an essential natural resource for research on the response of banana plants to TR4 infection, the susceptible mechanism of BX, and the underlying pathogen control methods.

Extensive work in model plants has shown that metabolites such as the hypersensitive response signal molecules salicylic acid (SA) and

Corresponding author: M. Peng; E-mail: pengming@itbb.org.cn

W. $\mathrm{Li}$ and $\mathrm{C}$. Li contributed equally to this work.

*The $\boldsymbol{e}$-Xtra logo stands for "electronic extra" and indicates that two supplementary tables and two supplementary figures are available online.

Accepted for publication 9 November 2016.

(c) 2017 The American Phytopathological Society jasmonic acid (JA) (Alvarez 2000); the growth-regulating phytohormones abscisic acid (ABA) (Adie et al. 2007; Xie et al. 2011), 3 -indoleacetic acid (IAA) (Park 2007), cytokinin (CTK), and gibberellic acid (GA) (Ha et al. 2012; Novak et al. 2013); the antioxidants glutathione and ascorbic acid (Bao et al. 2016; Kovacs et al. 2015; Sinha et al. 2015; Xu et al. 2013); the defense compounds polyphenol, phenolic acids, and flavonoids (García-Sánchez et al. 2012; Joshi et al. 2015); and the organic acids syringic acid, gallagic acid, and sinapic acid (Barding et al. 2013) are induced to respond to pathogens and active plant defense. During plant-pathogen interactions, signal molecules and phytohormones induce the expression of pathogenesis-related $(P R)$ genes. For instance, $P R-1, P R-2$, and $P R-5$ are SA induced whereas $P R-3, P R-4$, and $P R-12$, as well as polyphenol oxidase (PPO) activity, are regulated by JA (Bosch et al. 2014; Shah et al. 2001; Thomma et al. 1998).

In banana, plant resistance depends on the rate and extent of phenolic production and lignin deposition, as well as an increase in cell-wall strengthening-related enzymes (Beckman 1990; De Ascensao and Dubery 2000). Some resistant banana plants exhibit significantly increased cell-wall-associated phenolic compounds (van den Berg et al. 2007) in addition to an increase in soluble and wall-bound phenolics and phenolic polymers in banana roots as part of anti-F. oxysporum $\mathrm{f}$. sp. cubense defenses activation (de Ascensao and Dubery 2003).

Using high-throughput sequencing, numerous genes involved in defense response pathways, including SA, JA, ethylene (ET), and $P R$ genes, have been identified in the response of banana plants to F. oxysporum f. sp. cubense infection ( $\mathrm{Li}$ et al. 2012; $\mathrm{Li}$ et al. 2013a; Li et al. 2013b; Wang et al. 2012). Exogenous SA contributed to the resistance of BX to $F$. oxysporum $\mathrm{f}$. sp. cubense TR4 (Wang et al. 2015). Research also shows that thaumatin-like protein (TLP or $P R-5)$ and $\beta$-1,3-glucanase had higher expression levels in resistant species compared with the susceptible BX (Li et al. 2015a), and the transgenic banana plants with rice TLP gene shows an enhanced resistance to TR4 (Mahdavi et al. 2012). The levels of expression of $P R$ genes (for instance, $P R-5$ ), phenylalanine ammonia-lyase 3 (PAL3), and allene oxide synthease 2 (AOS2) are greatly increased in BX to TR4 infection compared with $F$. oxysporum $\mathrm{f}$. sp. cubense strain TR1 (nonvirulent to BX) infection (Li et al. 2013a). 
Although the defense response has been well studied in model plants, little information is available on the metabolic changes, transcriptional regulation, or physiological responses of bioactive and signaling compounds during infection of banana with $F$. oxysporum $\mathrm{f}$. sp. cubense TR4. In this study, we investigated changes in metabolic compounds and gene expression in susceptible and resistant banana infected with $F$. oxysporum f. sp. cubense through metabolomic, biochemical, and molecular biological methods. The results showed that the response differences between two banana species during TR4 infection included signal molecules, phytohormones, antioxidants, and phenolics. The comparative analysis also illustrated the dynamic profiles of metabolites and gene expression during the early stage of the interaction between Fusarium spp. and banana.

\section{Materials and Methods}

Plant materials. Susceptible BX banana is a Cavendish subgroup and the resistant species M. yunnanensis (YN) is a wild banana relative belonging to the M. acuminata subspecies (Häkkinen and Wang 2007). Banana plantlets were propagated by tissue culture under sterile conditions. Suckers were used for multiplication and rooting by placing them in plastic pots filled with soil and vermiculite $(1: 1)$. The plantlets were placed in a growth room at $28^{\circ} \mathrm{C}$ with a period of $16 \mathrm{~h}$ of light and $8 \mathrm{~h}$ of darkness and a light intensity of 5,000 lux for 90 days.

Fusarium strain and generation of the green fluorescent protein line. The strain TR4 VCG01213/16 was isolated from the Hainan Island of China by Dr. Junsheng Huang. The strain, transformed with green fluorescent protein (GFP), was constructed and kept in our research laboratory ( $\mathrm{Li}$ et al. 2013a). Protoplasts of TR4 were transformed through a method of polyethylene glycol/ $/ \mathrm{CaCl}_{2}$-mediated transformation, as described previously (Lorang et al. 2001; Xiao et al. 2009).

Pathogen preparation, inoculation, and microscopic observation of the infection process. The GFP-expressing strain was used for all infection processes of 90-day old plantlets. A small block of TR4 was transferred to potato dextrose agar (PDA) and grown at $28^{\circ} \mathrm{C}$ for $72 \mathrm{~h}$ in darkness. For inoculation, three wounds were artificially made into the root using a sterile dissecting needle and covered with a freshly prepared TR4 agar block of about $0.5 \mathrm{~cm}^{2}$ (Supplementary Fig. S1). For mock inoculation, the roots were wrapped with a PDA block without $F$. oxysporum f. sp. cubense. For microscopic examination, banana roots were washed with sterile, distilled water before being prepared for observation under a laser confocal microscope (Olympus FV10ASW) equipped for GFP detection $(488 \mathrm{~nm})$ and root autofluorescence detection (543 and $595 \mathrm{~nm}$ ). Roots were collected at 3, 27, and $51 \mathrm{~h}$ after inoculation for metabolomic analysis and RNA extraction. The roots were frozen in liquid nitrogen and stored at $-80^{\circ} \mathrm{C}$ until use.

Metabolomic analysis. Six treated and six mock-inoculated banana plantlets, including three to five roots per plant, were collected at the same time. Roots $(100 \mathrm{mg})$ were ground in liquid nitrogen and extracted with $800 \mu \mathrm{l}$ of $70 \%$ methanol ( $\mathrm{vol} / \mathrm{vol})$ in a sonication bath for $10 \mathrm{~min}$. The mixture was centrifuged at $12,000 \times \mathrm{g}$ for $10 \mathrm{~min}$. The supernatant was transferred to a new tube for analysis.

Metabolomic analysis was conducted by Shanghai Sensichip Infotech Co. through reversed-phase high-performance liquid chromatography (HPLC) (Agilent 1290) quadrupole time-of-flight mass spectrometry (Q-TOF-MS) with an electrospray ionization source (Agilent 6500). Separation was achieved with a C18 column (100 by $2.1 \mathrm{~mm}$, interior diameter $=1.8 \mu \mathrm{m}$; Waters) at $40^{\circ} \mathrm{C}$ using A, ultrapure water with $0.1 \%$ ( $\mathrm{vol} / \mathrm{vol}$ ) formic acid and $\mathrm{B}$, acetonitrile with $0.1 \%$ ( vol/vol) formic acid. The gradient program was 0 to $1 \mathrm{~min} 5 \% \mathrm{~B}, 1$ to 13 min linear gradient from 5 to $95 \% \mathrm{~B}$, and 13 to $15 \mathrm{~min} 95 \% \mathrm{~B}$.

Typical total ion chromatograms for each ionization technique were conducted in both positive and negative ion modes. MS parameters were $4.0 \mathrm{kV}$ capillary voltage and 35 and $50 \mathrm{kV}$ sampling cone for positive and negative modes, respectively, at $100^{\circ} \mathrm{C}$. Desolvation temperature was 350 and $300^{\circ} \mathrm{C}$ and the desolvation gas flow was 600 and 700 liter/h for positive and negative modes, respectively. The extraction cone voltage was set at $4 \mathrm{~V}$. The system was equipped with $0.03 \mathrm{~s}$ scan time, $0.02 \mathrm{~s}$ interscan time, and 50 to $1,000 \mathrm{~m} / \mathrm{z}$ scan range.
Metabolic data processing and analysis. The raw liquid chromatography (LC) data were processed using Mass-Hunter Qualitative Analysis software (version B.03.01) and the MS identification through the METLIN metabolite database (http://metlin.scripps.edu). Principal components analysis and orthogonal projection to latent structure discriminant analysis (OPLS-DA) were conducted by SIMCA-P+ software (version 11.0). A $t$ test $(P<0.05)$ was applied to determine statistically significant differences between groups.

Determination of phytohormone and phenolics content in banana plants. SA and methyl (Me)-JA were directly measured using a previous method, with modifications (Yang et al. 2005). Briefly, $5 \mathrm{~g}$ of ground fresh banana roots were extracted with $15 \mathrm{ml}$ of $80 \%$ (vol/vol) methanol containing $1 \%$ acetic acid (vol $/ \mathrm{vol})$ for $12 \mathrm{~h}$ at $4^{\circ} \mathrm{C}$. After centrifugation, the supernatant was extracted using a $3: 1$ mixture of $0.2 \mathrm{M}$ $\mathrm{Na}_{2} \mathrm{HPO}_{4} / \mathrm{H}_{3} \mathrm{PO}_{4}(\mathrm{vol} / \mathrm{vol})$ and $2 \mathrm{ml}$ of petroleum ether at $4^{\circ} \mathrm{C}$ for three times. The water phase was adjusted to $\mathrm{pH}=8.0$ by $\mathrm{Na}_{2} \mathrm{HPO}_{4}$ and was twice extracted with an equal volume of ethyl acetate. The ester phase was evaporated at $20^{\circ} \mathrm{C}$ and dissolved in $50 \%$ methanol (vol/vol) to $1 \mathrm{ml}$ for LC-MS analysis.

$\mathrm{ABA}, \mathrm{CTK}$, IAA, and GA were directly measured as described previously (Li et al. 2015b). SA and Me-JA were also analyzed by HPLC using a methanol $/ \mathrm{H}_{2} \mathrm{O} /$ phosphate mixture at 55:44.9:0.1(vol $\left./ \mathrm{vol} / \mathrm{vol}\right)$ and methanol $/ \mathrm{H}_{2} \mathrm{O} /$ acetic acid at 54:43.5:2.5 ( $\left.\mathrm{vol} / \mathrm{vol} / \mathrm{vol}\right)$, respectively, at 220 to $280 \mathrm{~nm}$. The chromatographic peaks were identified by a combination of LC (Ultimate 3000) and tandem MS (AmaZon SL) (LC-MS). The authentic standards were IAA (MW $=175.18),(+)$-ABA $(\mathrm{MW}=$ 264.32), transzeatin (CTK; MW = 219.28), GA (MW = 346.37), Me-JA (MW = 224.30), and SA (MW = 138.12) (Sigma-Aldrich).

For total phenolics measurement, fresh TR4-inoculated and mockinoculated roots $(1 \mathrm{~g})$ were ground and treated with $3 \mathrm{ml}$ of $60 \%$ methanol (vol/vol) using a slightly modified method (Pérez-Jiménez and Saura-Calixto 2005). Extraction was carried out in a shaking water bath at $80^{\circ} \mathrm{C}$ for $15 \mathrm{~min}$ under $380 \mathrm{rpm}$ for three times. Supernatant was collected by centrifuging at $12,000 \times g$ for $30 \mathrm{~min}$ and kept at $4^{\circ} \mathrm{C}$ for analysis. Total phenolic content was determined using the Folin-Ciocalteu method at $765 \mathrm{~nm}$ (Singleton and Rossi 1965).

RNA extraction and quantitative real-time polymerase chain reaction analysis. Total RNA was extracted from TR4-inoculated and mock-inoculated roots using the modified cetyltrimethylammonium bromide method (Ruan et al. 2011). First-strand cDNA synthesis was performed with $1.5 \mu \mathrm{g}$ of total RNA using the FastQuant RT kit according to the manufacturer's instruction (KR106; Tiangen). Reactions were run on an Applied Biosystems StepOne Real-Time polymerase chain reaction (PCR) system with a 96-well plate. Gene-specific primers were designed based on the gene sequence information (http://banana-genome-hub.southgreen.fr/). Specific genes and primers for quantitative real-time (RT-q)PCR are listed in Supplementary Table S1.

The PCR was $95^{\circ} \mathrm{C}$ for $30 \mathrm{~s}$, followed by 40 cycles of $5 \mathrm{~s}$ at $95^{\circ} \mathrm{C}$ and $30 \mathrm{~s}$ at 58 to $60^{\circ} \mathrm{C}$. At the end of each experiment, a melt-curve analysis was performed using the default parameters $\left(15 \mathrm{~s}\right.$ at $95^{\circ} \mathrm{C}$, $1 \mathrm{~m}$ at $55^{\circ} \mathrm{C}$ to $95^{\circ} \mathrm{C}$ in $0.3^{\circ} \mathrm{C}$ increments, and $15 \mathrm{~s}$ at $\left.95^{\circ} \mathrm{C}\right)$. The relative expression levels of the target genes were calculated by the $2^{-\Delta \Delta \mathrm{Ct}}$ method (Livak and Schmittgen 2001). The $\beta$-actin gene and glyceraldehydes-3-phosphate dehydrogenase 2 were employed as internal references to normalize the transcriptional levels of target genes.

\section{Results}

F. oxysporum f. sp. cubense TR4 infection process in BX and YN banana plants. $F$. oxysporum $\mathrm{f}$. sp. cubense usually invades the entire vascular system of pseudostems through damaged roots. GFP-expressing TR4 was used to monitor the pathogen infection processes between $\mathrm{YN}$ and $\mathrm{BX}$, in tissues with similar fluorescence intensity, under a confocal microscope. Spores and hyphae of TR4 had attached to the epidermal cells of the banana roots $3 \mathrm{~h}$ after infection (Fig. 1A and E), and had penetrated into the cortex parenchyma at $27 \mathrm{~h} \mathrm{(Fig.} \mathrm{1B} \mathrm{and} \mathrm{F).} \mathrm{At} 51 \mathrm{~h}$, a greater amount of hyphae and spores were in the cells of the banana roots and into the endodermis of the vascular tissues in both BX (Fig. 1C) and YN (Fig. 1G). Hyphae were also observed in the endodermis of the vascular tissues 
$5 \mathrm{~mm}$ above the infection sites of both BX (Fig. 1D) and YN (Fig. $1 \mathrm{H})$ after $51 \mathrm{~h}$. No apparent difference in infection process between $\mathrm{BX}$ and $\mathrm{YN}$ was observed in our experiment.

Molecular signaling and phytohormone metabolite profiles. A series of pairwise OPLS-DA were applied to maximize the discrimination between experimental samples and to focus on metabolic variations significantly contributing to the resulting classifications. The differences between the control and infected groups in the OPLS-DA suggested that significant biochemical perturbation occurred in these samples (Supplementary Fig. S2). All significantly changed compounds $(P<0.05$, with the variable importance in the projection $>$ 1.0) between the TR4-treated and mock-inoculated banana plants are listed in Supplementary Table S2.

Investigation of the signal molecules and phytohormone metabolites showed that compounds related to SA and JA seemed to be inhibited at $3 \mathrm{~h}$ after inoculation in the susceptible BX (Table 1). In BX, some SA- and JA-related compounds were generally higher at $27 \mathrm{~h}$ than at $3 \mathrm{~h}$ after inoculation, such as SA, formylsalicylic acid, $\beta$-D-glucopyranosyl -11-hydroxy jasmonic acid, and Me-JA. However, SA and formyl-SA decreased to 0.74- and 0.52-fold higher than mock-inoculated, respectively, at $51 \mathrm{~h}$ in BX. In the resistant YN, SA and formyl-SA were induced at $3 \mathrm{~h}$ and remained at higher levels throughout the infection process (Table 1). Formyl-SA showed a larger fold change than SA at $51 \mathrm{~h}$ after being inoculated in $\mathrm{YN}$. $\beta$-D-glucopyranosyl-11-hydroxyjasmonic acid and Me-JA were up slightly at $3 \mathrm{~h}$ but decreased at $27 \mathrm{~h}$ after inoculation.

Some plant growth regulators also exhibited different profiles during F. oxysporum $\mathrm{f}$. sp. cubense infection, depending on the plant material (Table 1). For example, ABA had a slight decrease at $3 \mathrm{~h}$ but increased from 27 to $51 \mathrm{~h}$ after inoculation in $\mathrm{BX}$, while the levels of $\mathrm{ABA}$ glucose ester increased significantly to 1.51 -fold in the BX cultivar throughout the early stages of infection. In contrast, the levels of $\mathrm{ABA}$ and $\mathrm{ABA}$ glucose ester all decreased in $\mathrm{YN}$ compared with the mock-inoculated YN. The content of zeatin (transzeatin) showed a small increase in BX but considerable upregulation in YN $27 \mathrm{~h}$ after inoculation. The levels of tryptophan involved in the biosynthesis of IAA were also significantly upregulated in the infected $\mathrm{BX}$ at both the beginning of inoculation and $51 \mathrm{~h}$ after inoculation. The noteworthy difference was that tryptophan decreased in BX but increased in YN (up 3.76-fold) $27 \mathrm{~h}$ after inoculation, whereas it increased in BX but decreased in $\mathrm{YN}$ at 3 and $51 \mathrm{~h}$ after inoculation. In contrast, levels of compounds related to GA were not significantly different under our criteria.

Concentrations of signal molecules and phytohormones in banana plants during $F$. oxysporum $f$. sp. cubense infection. The directly measured concentrations of SA, Me-JA, ABA, CTK, IAA, and GA fluctuated throughout the interaction between banana plants and
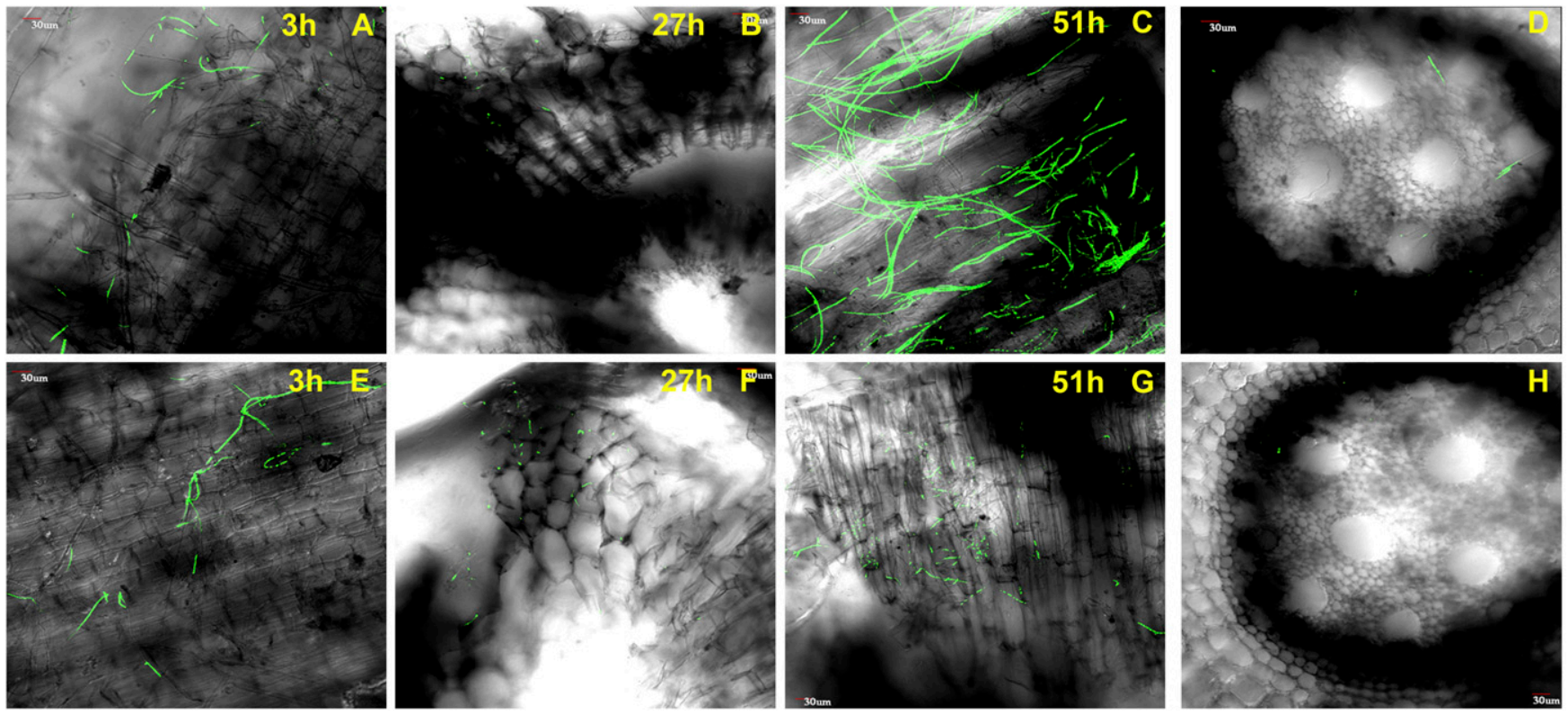

Fig. 1. Examination of the infection process using green fluorescent protein-expressing Fusarium oxysporum f. sp. cubense TR4. A to D, BaXi and $E$ to $H, M u s a$ yunnanensis. A, C $\mathrm{E}$, and $\mathrm{G}$ were longitudinal sections and $\mathrm{B}, \mathrm{D}, \mathrm{F}$, and $\mathrm{H}$ were transverse sections of banana plant roots.

Table 1. Phytohormone metabolites detected by liquid chromatography quadrupole time-of-flight mass spectrometry in banana infected by Fusarium oxysporum f. sp. cubense strain TR4 ${ }^{\mathrm{a}}$

\begin{tabular}{|c|c|c|c|c|c|c|c|c|c|}
\hline \multirow[b]{2}{*}{ VIP } & \multirow[b]{2}{*}{ RT (min) $)^{\mathbf{c}}$} & \multirow[b]{2}{*}{ Mass } & \multirow[b]{2}{*}{ Name } & \multicolumn{3}{|c|}{ Fold changes $(\mathrm{BX})$} & \multicolumn{3}{|c|}{ Fold changes (YN) } \\
\hline & & & & $3 \mathbf{h}$ & $27 \mathrm{~h}$ & $51 \mathrm{~h}$ & $3 \mathrm{~h}$ & $27 \mathrm{~h}$ & $51 \mathrm{~h}$ \\
\hline 1.713 & 4.710 & 138.032 & Salicylic acid & $0.62 \downarrow$ & $1.82 \uparrow$ & $0.74 \downarrow$ & $3.01 \uparrow$ & $2.13 \uparrow$ & $1.20 \uparrow$ \\
\hline 2.049 & 4.442 & 166.027 & Formylsalicylic acid & $0.65 \downarrow$ & $1.32 \uparrow$ & $0.52 \downarrow$ & $1.61 \uparrow$ & $1.26 \uparrow$ & $1.43 \uparrow$ \\
\hline 1.889 & 5.020 & 388.173 & $\beta$-D-glucopyranosyl-11-hydroxyjasmonic acid & $0.60 \downarrow$ & $2.09 \uparrow$ & $2.06 \uparrow$ & 1.33 & $0.56 \downarrow$ & $1.47 \uparrow$ \\
\hline 1.208 & 10.130 & 224.142 & Methyl jasmonate & $0.91 \downarrow$ & $1.21 \uparrow$ & 1.12 & 1.24 & $0.83 \downarrow$ & $1.89 \uparrow$ \\
\hline 1.578 & 4.520 & 264.137 & Abscisic acid & $0.85 \downarrow$ & $1.11 \uparrow$ & 1.02 & $0.95 \downarrow$ & $0.73 \downarrow$ & $0.81 \downarrow$ \\
\hline 1.710 & 5.930 & 426.189 & Abscisic acid glucose ester & $1.84 \uparrow$ & $1.85 \uparrow$ & $2.70 \uparrow$ & 0.48 & $0.38 \downarrow$ & $0.22 \downarrow$ \\
\hline 1.394 & 2.950 & 219.111 & Zeatin (transzeatin) & 1.17 & 1.27 & 1.04 & $0.86 \downarrow$ & $1.38 \uparrow$ & 0.91 \\
\hline 1.812 & 4.431 & 204.090 & Tryptophan & $1.48 \uparrow$ & $0.62 \downarrow$ & $1.66 \uparrow$ & $0.75 \downarrow$ & $3.76 \uparrow$ & $0.46 \downarrow$ \\
\hline
\end{tabular}

${ }^{\text {a }}$ Fold change was the peak area ratio of the $F$. oxysporum f. sp. cubense-inoculated banana over the mock-inoculated banana according to the results of highperformance liquid chromatography. $\mathrm{BX}=\mathrm{BaXi}$ and $\mathrm{YN}=$ Musa yunnanensis. $\mathrm{Up}$ and down arrows indicate significant increasing and decreasing, respectively $(P<0.05)$.

${ }^{\mathrm{b}}$ VIP $=$ variable importance in the projection $(>1)$.

${ }^{c}$ Retention time. 
TR4 (Fig. 2). The levels of SA increased in the infected YN over the mock-inoculated YN (Fig. 2A, circles). The increase in SA content in the infected YN was as high as 2.6-fold over that in the mockinoculated YN. In the susceptible BX, the concentration of SA did not significantly change between the infected and mock-inoculated $\mathrm{BX}$ at the beginning of inoculation. Interestingly, SA was lower in the infected BX compared with the mock-inoculated BX at 27 and $51 \mathrm{~h}$ after inoculation (Fig. 2A, squares).

Me-JA showed a peak increase in the infected BX plants at $27 \mathrm{~h}$ after inoculation, while remaining flat in the infected YN plants from 3 to $27 \mathrm{~h}$ after inoculation and increasing greatly at $51 \mathrm{~h}$ (Fig. 2B). The content of Me-JA increased in the mock-inoculated $\mathrm{YN}$ at $27 \mathrm{~h}$ after inoculation (1.14-fold over the infected YN). However, the level of Me-JA (119.13 ng g fresh weight $\left.[\mathrm{fwt}]^{-1}\right)$ in the infected YN greatly increased over the mock-inoculated YN at $51 \mathrm{~h}$ after inoculation and was higher than that of SA. Furthermore, the levels of Me-JA were higher in the infected YN than in the infected BX $\left(80.12 \mathrm{ng} \mathrm{g} \mathrm{fwt}^{-1}\right)$ at $51 \mathrm{~h}$ after inoculation.

The concentration of $\mathrm{ABA}$ in $\mathrm{BX}$ was clearly higher than that in YN 3 to $51 \mathrm{~h}$ after inoculation (Fig. 2C). The infected BX had higher ABA content than the mock-inoculated $\mathrm{BX}$ at $27 \mathrm{~h}$ after inoculation, while the infected YN had lower levels of ABA than the mockinoculated YN. Furthermore, the peak content of ABA (242.13 ng g $\mathrm{fwt}^{-1}$ ) in the infected $\mathrm{BX}$ at $27 \mathrm{~h}$ was twofold higher than in the infected YN (95.89 $\mathrm{ng} \mathrm{g} \mathrm{fwt}^{-1}$ ). This measurement was consistent with the metabolomic data that showed that $\mathrm{YN}$ had lower fold changes in ABA levels than did BX from 27 to $51 \mathrm{~h}$ after inoculation. The lower ABA concentration in the resistant plants and the smaller increase in ABA levels after infection in resistant plants compared with the mock-inoculated banana might be important in the banana mechanisms of resistance to $F$. oxysporum $\mathrm{f}$. sp. cubense.

In contrast, IAA in the infected YN was higher than that in the infected BX throughout the time course. IAA reached its maximum (241.45 $\mathrm{ng} \mathrm{g} \mathrm{fwt}^{-1}$ ) at $27 \mathrm{~h}$ in the infected YN. The response was the opposite in the susceptible cultivar, in which IAA in the infected BX decreased to levels lower than in the mock-inoculated BX. At 51 $\mathrm{h}$, the two cultivars showed change similar to those at $3 \mathrm{~h}$ (Fig. 2D).

The concentrations of CTK and $\mathrm{GA}_{3}$ in banana were lower in the resistant $\mathrm{YN}$ than in the susceptible $\mathrm{BX}$ during the whole infection.
The level of CTK in the infected YN was higher than that in the mock-inoculated YN only at $27 \mathrm{~h}$, whereas it was higher in the infected BX than in the mock-inoculated BX from 3 to $51 \mathrm{~h}$ after inoculation (Fig. 2E). As for $\mathrm{GA}_{3}$, it seemed that all infected banana plants had lower levels than the mock-inoculated banana plants. Furthermore, the resistant $\mathrm{YN}$ had lower levels of $\mathrm{GA}_{3}$ than the susceptible BX during the whole infection (Fig. 2F).

Profiles of phenolic compounds and antioxidants in banana roots responding to $F$. oxysporum f. sp. cubense infection. The polyphenols syringic acid, gallagic acid, and sinapic acid were all induced in the infected BX at $3 \mathrm{~h}$ (Table 2) but syringic and gallagic acids were downregulated at $27 \mathrm{~h}$. In the resistant YN, these compounds remained higher in the infected $\mathrm{YN}$ than in the mockinoculated from 3 to $51 \mathrm{~h}$. Gallagic acid was increased 1.43- and 1.54-fold at 27 and $51 \mathrm{~h}$, respectively, and syringic acid was up 1.78 -fold at $3 \mathrm{~h}$ after inoculation.

Flavonoids and catechins were also regulated by $F$. oxysporum f. sp. cubense infection in banana plants. These compounds were greatly increased $3 \mathrm{~h}$ after BX was inoculated with TR4 but only two compounds (trihydroxy-flavone-glucoside and pyrocatechol) were increased at $27 \mathrm{~h}$, and three were significantly decreased at $51 \mathrm{~h}$ after inoculation (Table 3 ). These compounds were significantly upregulated in the infected $\mathrm{YN}$ at $27 \mathrm{~h}$ after inoculation. In particular, in the infected $\mathrm{YN}$, trihydroxyflavone glucoside was increased 2.59fold at $27 \mathrm{~h}$ and 1.74-fold at $51 \mathrm{~h}$, glucopyranosylcatechin was up 2.72 -fold at $27 \mathrm{~h}$, and pyrocatechol was up 1.66 -fold at $51 \mathrm{~h}$. Furthermore, phyllofavanine and pyrocatechol were not detected in the mock-inoculated YN. The profile of these compounds implied that the resistant banana cultivar YN upregulated these compounds in response to $F$. oxysporum f. sp. cubense infection.

The concentration of total phenolics in banana plants during infection by TR4 was also measured. Total phenolic content in the infected banana roots (Fig. 2, filled shapes) was higher than in the mock-inoculated roots in both varieties. Furthermore, the phenolics were higher in the infected $\mathrm{YN}$ than in the infected BX from 3 to $51 \mathrm{~h}$ after inoculation (Fig. 3). The concentration of total phenolics in the infected $\mathrm{YN}$ was 1.4-fold higher than in the infected $\mathrm{BX}$ at $27 \mathrm{~h}$ and 1.5 -fold higher at $51 \mathrm{~h}$ after inoculation. It was interesting that the concentration of total phenolics increased gradually in the
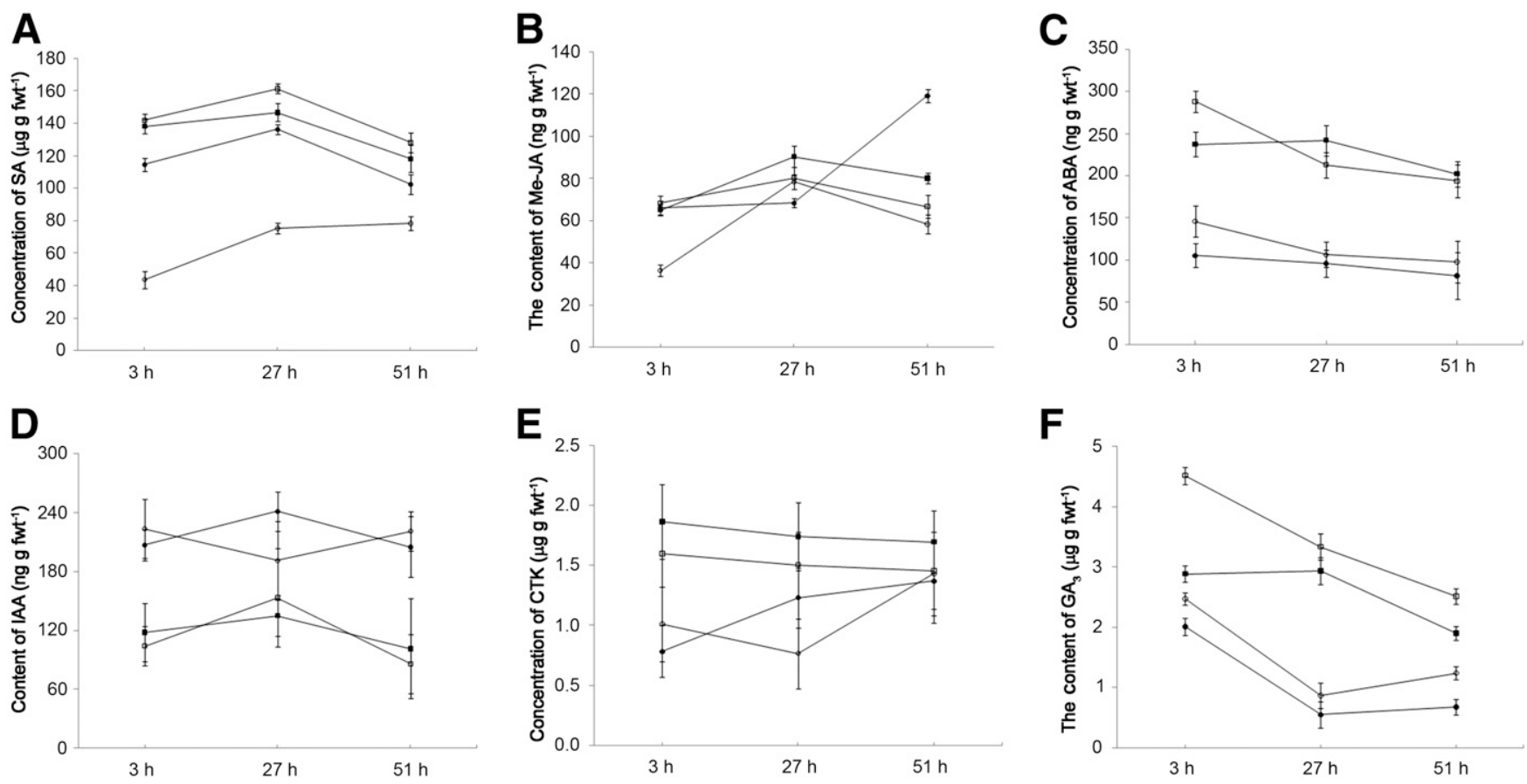

Fig. 2. Concentration of A, salicylic acid (SA); B, methyl-jasmonic acid (Me-JA); C, abscisic acid (ABA); D, cytokinin (CTK); E, 3-indoleacetic acid (IAA); and F, gibberellic acid (GA) during banana infection by Fusarium oxysporum f. sp. cubense through high-performance liquid chromatography mass spectrometry. Error bars represent standard error from six samples and fwt = fresh weight. Infected BaXi (BX, filled square) and mock-inoculated BX (open square). Infected Musa yunnanensis (YN, filled circle) and the mock-inoculated YN (open circle). 
infected YN but decreased gradually in the infected BX. The concentration of total phenolics in the mock-inoculated $\mathrm{YN}$ was also higher than in the mock-inoculated BX from 27 to $51 \mathrm{~h}$. The levels in the mockinoculated YN (51 h) were also higher than in the infected BX, indicating that the response may be mediated through wounding. The trends detected via Folin-Ciocalteu for total phenolics were almost consistent with the results of the metabolomic analyses in Table 2.

We also found that glutathione and ascorbic acid showed significant changes in our metabolomic data during the infection process. For instance, in the infected YN banana plant, oxidized glutathione was significantly upregulated 1.34 -fold at $3 \mathrm{~h}$ and 1.59 -fold at $27 \mathrm{~h}$ after inoculation. Ascorbic acid increased 1.18- and 1.62-fold in $\mathrm{BX}$ at 3 and $27 \mathrm{~h}$ after inoculation, respectively, compared with mock-inoculated susceptible plants. The data implied that different antioxidants play different roles in banana plants susceptible or resistant to $F$. oxysporum f. sp. cubense infection (Table 3 ).

The relationship between gene expression and metabolite levels. The expression levels of the genes encoding PAL, isochorismate synthase (ICS), and nonexpressor of PR protein 1 (NPR1), all involved in the biosynthesis and regulation of SA, were investigated 3, 27, and $51 \mathrm{~h}$ after infection with $F$. oxysporum $\mathrm{f}$. sp. cubense (Fig. 4 ). Of the nine genes analyzed, expression of $P A L 1$ showed the highest increase in the infected plants compared with the mock-inoculated plants (nearly 20fold). PAL2 was also induced $3 \mathrm{~h}$ after inoculation in both YN (4.6-fold) and BX (1.3-fold). All PAL gene expression levels increased more in the infected $\mathrm{YN}$ than in the infected $\mathrm{BX}$ at the beginning of infection, which was in accordance with the higher content of SA in the infected YN banana plants at $3 \mathrm{~h}$ (Table 1). Most SA biosynthesis genes, except PAL1 and $P A L 2$, had decreased expression levels at $51 \mathrm{~h}$ after inoculation in the infected YN. Relatively small changes $(<2.0$-fold) in ICS and $N P R I$ expression levels were found in the infected plants compared with their mock-inoculated counterparts at $3 \mathrm{~h}$ but significant increases were found at $27 \mathrm{~h}$, especially in the infected $\mathrm{YN}$.

Genes involved in the biosynthesis of JA were also analyzed, including lipoxygenases $(L O X)$, acyl-CoA oxidase $(A C O), A O S$, allene oxide cyclases $(A O C)$, and 12-oxophytodienoate reductases (12$O P R$ ) (Fig. 5). Most of the genes, except LOX1.1-1, LOX1.1-2, and $L O X 1.1-4$, were more highly induced in the infected $\mathrm{YN}$ than in the infected BX at the early stage of infection $(3 \mathrm{~h})$, which was consistent with the change of Me-JA shown in Figure 2B. At $27 \mathrm{~h}$, the expression levels of LOX1.1-1, LOX1.1-2, and LOX1.1-4 increased over twofold in the infected $\mathrm{BX}$ compared with the mock-inoculated $\mathrm{BX}$, a higher change than in YN. ACO-2, AOS-5, AOC3-1, and 12-OPR-3 also had greater fold changes in the infected $\mathrm{BX}$, implying that they also influence the higher level of Me-JA in BX at $27 \mathrm{~h}$ (Fig. 2B). The expression levels of $A O S-2, A O C 3-1$, and $A O C 3-2$ genes were higher at $51 \mathrm{~h}$ than at 3 or $27 \mathrm{~h}$ in the infected $\mathrm{BX}$, while $12-O P R-4$ and $A O S-5$ showed stable expression levels at 27 to $51 \mathrm{~h}$. In the YN cultivar, it was notable that LOX1.1-3, 2.3, AOC3-1, 12-OPR-1, and 12-OPR-2 had high fold changes in the infected $\mathrm{YN}$ at the early $(3 \mathrm{~h})$ and late (51 h) time points, while $A O S-3$ and $A O S-4$ had the highest fold change at $27 \mathrm{~h}$. The expression levels of ACO-1, ACO-2, AOS-1, AOS-5, and $12-O P R-3$ gradually decreased in the infected $\mathrm{YN}$ over the time course, whereas $A O S-1$ and $12-O P R-4$ showed stable expression levels between the infected and mock-inoculated YN.

The expression levels of genes encoding xanthoxin dehydrogenase (ABA2) and aldehyde oxidase (AAO), catalyzing the last two steps of ABA biosynthesis, were analyzed (Fig. 6). The fold change of $A B A 2$ and $A A O$ over mock was higher in $\mathrm{BX}$ than in $\mathrm{YN}$. The lower fold change $(<1)$ of these genes in the infected YN during the whole infection was in accordance with the changes in ABA levels in Figure 2C. The flavin monooxygenase genes $(Y U C$; functioning downstream in IAA production) YUC5 and YUC6 both showed the highest change at $3 \mathrm{~h}$ after infection in BX and YN, and then decreased, especially YUC5 (Fig. 6). In the infected banana plants, isopentenyltransferase (IPT) and 2-oxoglutarate 3-dioxygenase (GA3ox) both showed lower expression levels compared with the mock-inoculated banana plants $(<1)$. The changes in $I P T$ expression in the infected $\mathrm{YN}$ were, for the most part, greater than in the infected BX, whereas those of GA3ox were less than in the infected BX (Fig. 6). The expression profile of these genes

Table 2. Phenolic compounds detected by liquid chromatography quadrupole time-of-flight mass spectrometry in banana infected by Fusarium oxysporum f. sp. cubense strain TR4 ${ }^{\mathrm{a}}$

\begin{tabular}{|c|c|c|c|c|c|c|c|c|c|}
\hline \multirow[b]{2}{*}{ VIPb } & \multirow[b]{2}{*}{ RT $(\min )^{c}$} & \multirow[b]{2}{*}{ Mass } & \multirow[b]{2}{*}{ Name } & \multicolumn{3}{|c|}{ Fold changes $(\mathrm{BX})$} & \multicolumn{3}{|c|}{ Fold changes (YN) } \\
\hline & & & & $3 \mathbf{h}$ & $27 \mathrm{~h}$ & $51 \mathrm{~h}$ & $3 \mathrm{~h}$ & $27 \mathrm{~h}$ & $51 \mathrm{~h}$ \\
\hline 1.903 & 3.45 & 198.05 & Syringic acid & $1.82 \uparrow$ & 0.97 & 0.88 & 1.78 & 1.28 & $1.38 \uparrow$ \\
\hline 1.727 & 0.85 & 604.011 & Gallagic acid & $1.14 \uparrow$ & 0.88 & 1.10 & $1.57 \uparrow$ & $1.43 \uparrow$ & $1.54 \uparrow$ \\
\hline 1.602 & 4.057 & 224.062 & Sinapic acid & $1.61 \uparrow$ & $1.57 \uparrow$ & 1.06 & $0.41 \downarrow$ & 0.72 & $0.21 \downarrow$ \\
\hline 1.982 & 16.5 & 168.04 & Vanillic acid & 0.96 & $1.25 \uparrow$ & 1.04 & 1.05 & 0.99 & $1.20 \uparrow$ \\
\hline 1.533 & 5.3 & 346.11 & Dihydroxy-trimethoxyflavanone & $1.50 \uparrow$ & 1.04 & $0.41 \downarrow$ & 1.06 & $2.12 \uparrow$ & $1.60 \uparrow$ \\
\hline 2.281 & 0.745 & 432.113 & Trihydroxyflavone-glucoside & $1.84 \uparrow$ & $1.49 \uparrow$ & 1.04 & $3.03 \uparrow$ & $2.59 \uparrow$ & $1.74 \uparrow$ \\
\hline 1.756 & 8.13 & 660.185 & Phylloflavanine & 1.12 & 0.71 & 0.76 & $0.19 \downarrow$ & ND & 0.86 \\
\hline 1.847 & 6.74 & 110.037 & Pyrocatechol & 1.00 & $1.72 \uparrow$ & 1.23 & $1.31 \uparrow$ & ND & $1.66 \uparrow$ \\
\hline 1.649 & 5.83 & 452.131 & Glucopyranosylcatechin & $2.00 \uparrow$ & $0.46 \downarrow$ & 0.68 & $1.62 \uparrow$ & $2.72 \uparrow$ & 1.06 \\
\hline
\end{tabular}

${ }^{a}$ Fold change was the peak area ratio of the $F$. oxysporum f. sp. cubense-inoculated banana over the mock-inoculated banana according to the results of highperformance liquid chromatography. $\mathrm{BX}=\mathrm{BaXi}$ and $\mathrm{YN}=$ Musa yunnanensis. $\mathrm{Up}$ and down arrows indicate significant increasing and decreasing, respectively. ND means not detected in the mock-inoculated YN.

${ }^{\mathrm{b}}$ VIP $=$ variable importance in the projection $(>1)$.

${ }^{\mathrm{c}}$ Retention time.

Table 3. Antioxidants detected by liquid chromatography quadrupole time-of-flight mass spectrometry in banana infected by Fusarium oxysporum f. sp. cubense strain TR4 $4^{\mathrm{a}}$

\begin{tabular}{|c|c|c|c|c|c|c|c|c|c|}
\hline \multirow[b]{2}{*}{ VIP'b } & \multirow[b]{2}{*}{$\mathbf{R T}^{\mathrm{c}}$} & \multirow[b]{2}{*}{ Mass } & \multirow[b]{2}{*}{ Name } & \multicolumn{3}{|c|}{ Fold changes (BX) } & \multicolumn{3}{|c|}{ Fold changes (YN) } \\
\hline & & & & $6 \mathrm{~h}$ & $24 \mathrm{~h}$ & $48 \mathrm{~h}$ & $6 \mathrm{~h}$ & $24 \mathrm{~h}$ & $48 h$ \\
\hline 1.093 & 1.05 & 612.152 & Glutathione, oxidized & 1.12 & 0.94 & 1.20 & $1.34 \uparrow$ & $1.59 \uparrow$ & $0.67 \downarrow$ \\
\hline 2.447 & 0.98 & 338.09 & L-ascorbic acid-2-glucoside & $1.18 \uparrow$ & $1.62 \uparrow$ & $0.77 \downarrow$ & $0.74 \downarrow$ & 0.96 & $0.52 \downarrow$ \\
\hline
\end{tabular}

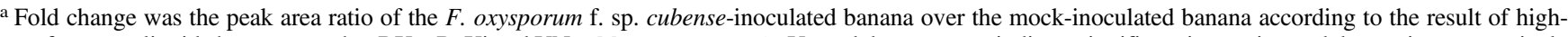
performance liquid chromatography. $\mathrm{BX}=\mathrm{BaXi}$ and $\mathrm{YN}=$ Musa yunnanensis. Up and down arrows indicate significant increasing and decreasing, respectively $(P<0.05)$

${ }^{\mathrm{b}}$ VIP $=$ variable importance in the projection $(>1)$.

${ }^{c}$ Retention time in minutes. 
was in accordance with the concentration changes seen for CTK and $\mathrm{GA}_{3}$ (Fig. 2E and F).

We also investigated the expression levels of dehydroascorbate reductases (DHAR) and monodehydroascorbate reductases (MDHAR) (Fig. 7). DHAR genes all showed lower expression levels in the infected BX compared with the mock-inoculated BX but increased expression levels in the infected $\mathrm{YN}$, especially from 3 to $27 \mathrm{~h}$ after

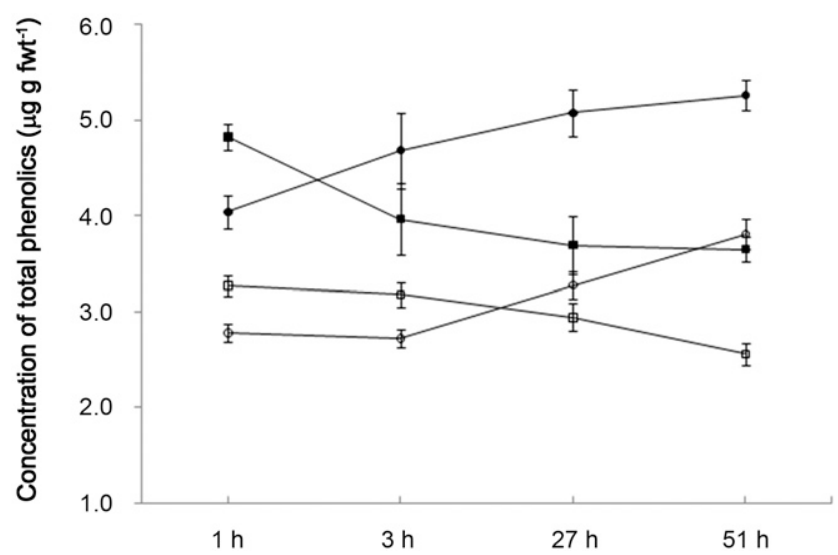

Fig. 3. Concentration of total phenolics during banana infection by Fusarium oxysporum f. sp. cubense through Folin-Ciocalteu method. Error bars represent standard error from six samples. Infected BaXi (BX, filled square) and mock-inoculated BX (open square). Infected Musa yunnanensis (YN, filled circle) and the mock-inoculated YN (open circle). infection. It was intriguing that the change in expression levels of the MDHAR genes showed opposite trends compared with those of the DHAR genes in the infected $\mathrm{BX}$ and YN cultivars.

Expression levels of PR genes. The expression of some wellknown PR genes was investigated in the $F$. oxysporum f. sp. cubensesusceptible BX and -resistant YN banana plants (Fig. 8). PRl, an SA-dependent gene, was upregulated, especially in the infected YN. It was obvious that $P R 2$, encoding endo- $(1,4)-\beta$-glucanase; $P R 5-1$ and $P R 5-2$, encoding thaumatin-like proteins; and $P R 9$, encoding peroxidase were strongly induced by TR4, especially $27 \mathrm{~h}$ after infection. Furthermore, the increases in the expression levels of these $P R$ genes were higher in the infected $\mathrm{YN}$ than in the infected BX. $P R 2$ and $P R 5$ reached peak expression at $27 \mathrm{~h}$, while $P R 4$, encoding endochitinase, and $P R 9$ showed further increases in expression over the course of the inoculation. Analysis of the expression levels of PR12 genes encoding defensin-like protein (PDF) showed that $P D F 2.2$ was also higher in the infected $\mathrm{YN}$, whereas $P D F 2.3$ was lower in the infected banana plants compared with the mock-inoculated plants.

$P P O$ genes encoding polyphenoloxidase were also greatly induced in the infected YN. For instance, $51 \mathrm{~h}$ after infection, $P P O-1$ was found to be upregulated nearly 20 -fold; $P P O-2$ was up to 20 - and 35 -fold at $27 \mathrm{~h}$ and $51 \mathrm{~h}$, respectively; and $P P O-3$ increased over 8 -fold at 27 and $51 \mathrm{~h}$ during the infection. In the infected BX cultivar, these genes had lower fold changes in their expression levels.

\section{Discussion}

Fusarium wilt caused by F. oxysporum f. sp. cubense is an extremely serious disease that limits the yield of banana fruit. Management of
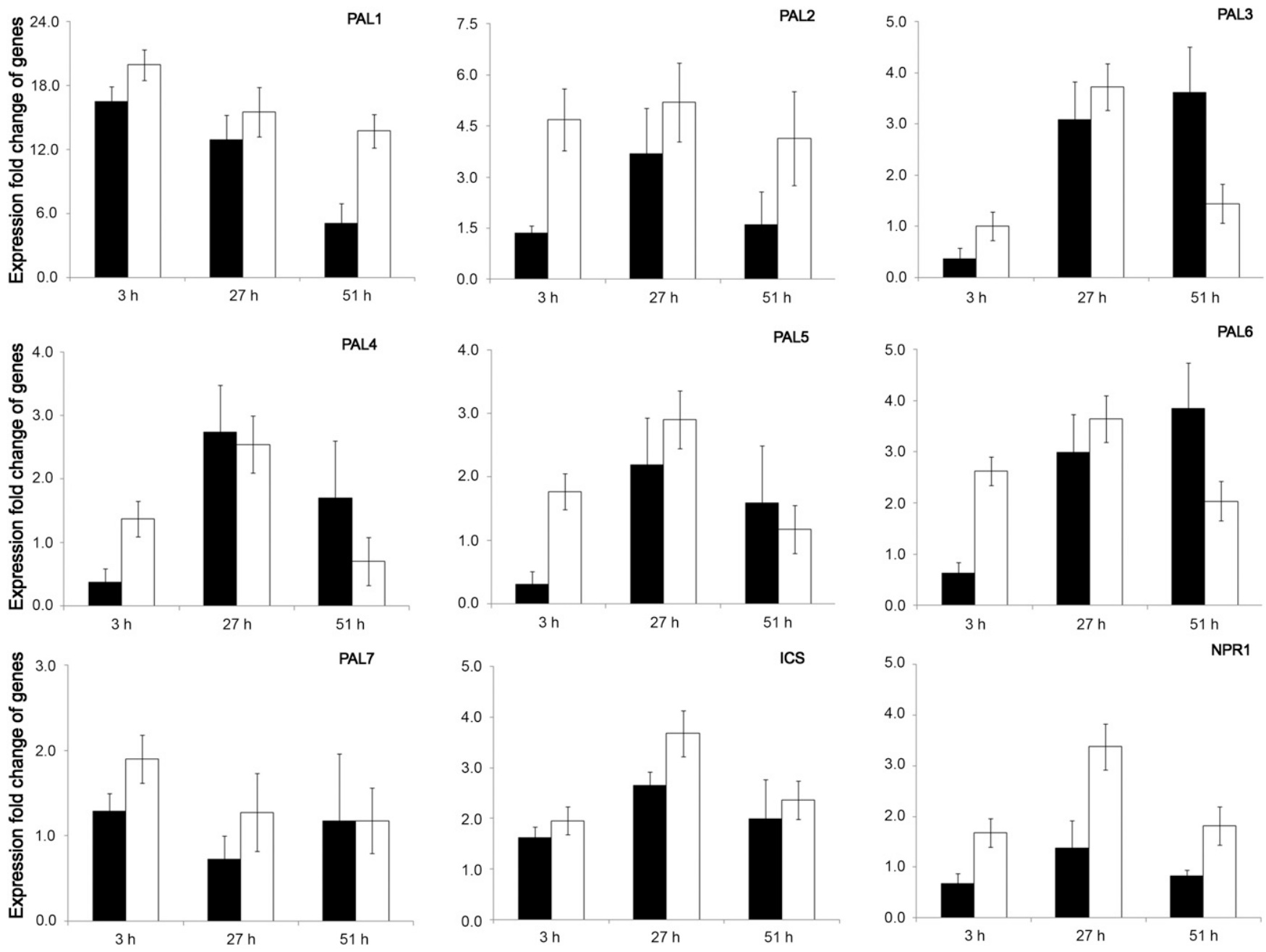

Fig. 4. Expression fold changes of genes involved in the biosynthesis of salicylic acid during banana infection by Fusarium oxysporum f. sp. cubense. Error bars represent standard error from six samples. BaXi (filled column) and Musa yunnanensis (open column). The value was the ratio of the infected over the mock-inoculated banana plants. PAL $=$ phenylalanine ammonia lyase, ICS = isochorismate synthase, and NPR1 = nonpathogenesis-related protein 1. 
Fusarium wilt, including soil solarization and fumigation (Herbert and Marx 1990; Liu et al. 2012), fungicides (Nel et al. 2007), crop rotation (Su et al. 1986; Xin et al. 2014), and antagonistic microbes (Wang et al. 2013; Zhang et al. 2011), has been widely employed. Research on the response of banana plants to $F$. oxysporum $\mathrm{f}$. sp. cubense should contribute to the control of Fusarium wilt in banana planting.

Our results indicate that numerous metabolites were activated to coordinate the banana defense response to $F$. oxysporum $\mathrm{f}$. sp. cubense, especially signal transduction molecules. The role of the signaling pathways mediated by SA, JA, and ET in the Arabidopsis innate immune response has been well established (Glazebrook 2005). Treatment with SA enhances the resistance to $F$. oxysporum in tomato (Mandal et al. 2009). SA, ET, and JA signaling pathways interact in a positive way for Arabidopsis to resist banana $F$. oxysporum f. sp. cubense (Radhajeyalakshmi et al. 2014). In our study, the resistant species YN responded to TR4 infection with higher SA levels than did the susceptible BX during the entire infection process. Because there was no obvious difference in the number of hyphae and spores attached to the roots during early infection (the first 2 days) between $F$. oxysporum f. sp. cubense-susceptible BX and -resistant YN, the defense pathways
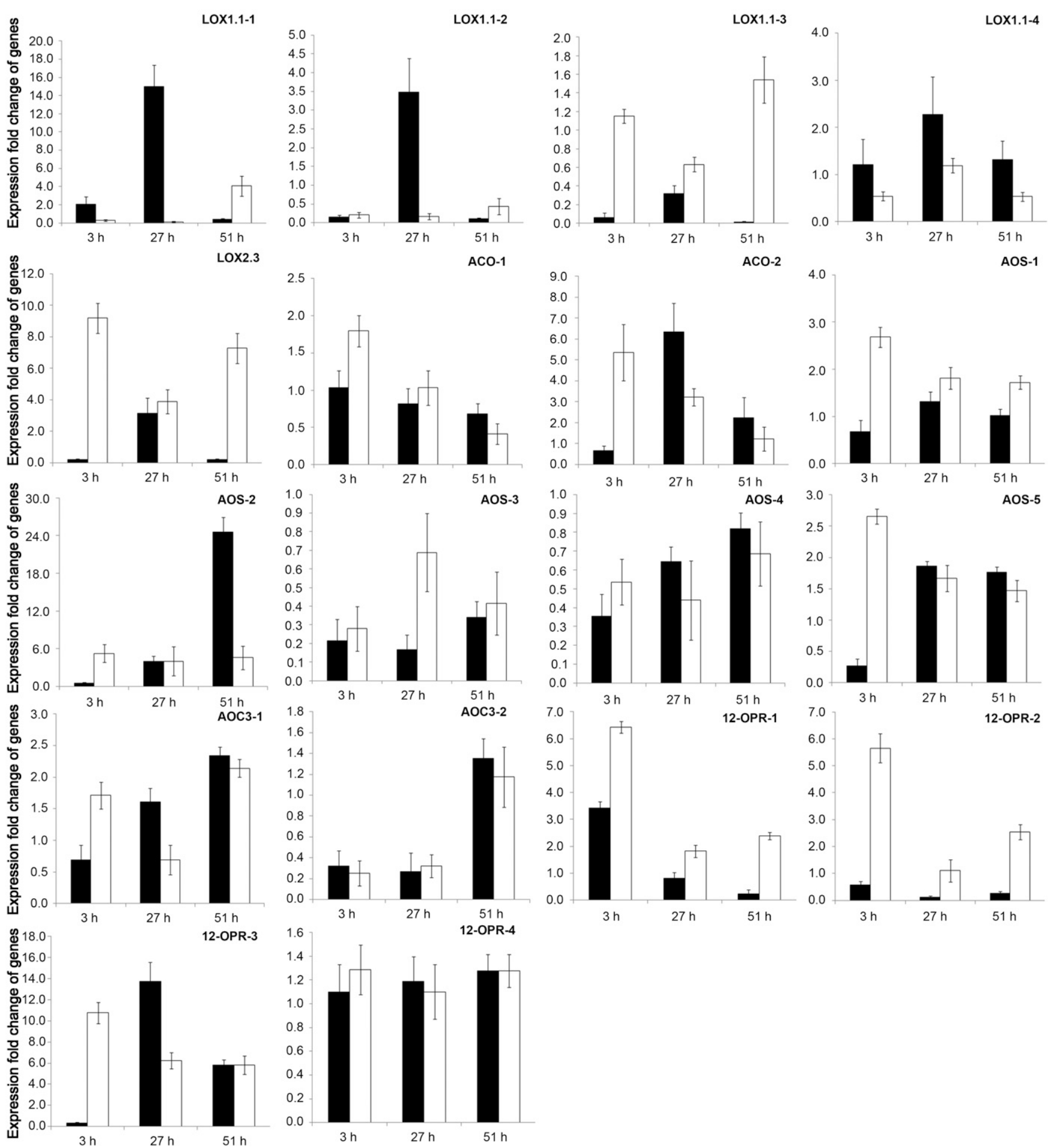

Fig. 5. Expression fold changes of genes involved in the biosynthesis of jasmonic acid during banana infection by Fusarium oxysporum f. sp. cubense strain TR4. Error bars represent standard error from six samples. The value was the ratio of the infected over the mock-inoculated banana plants. BaXi (filled column) and Musa yunnanensis (open column). $L O X=$ lipoxygenase, $A C O=$ acyl-CoA oxidase, $A O S=$ allene oxide synthase, $A O C=$ allene oxide cyclase, and 12-OPR = 12-oxophytodienoate reductase. 
induced by SA likely play an important positive role in banana against TR4. The JA pathway might involve the defense response in the banana-pathogen interaction, especially in the early stage, due to its higher level at $51 \mathrm{~h}$ after inoculation in YN (up 2.04-fold over the mock-inoculated YN).

Many hormones work together to modulate disease resistance (Robert-Seilaniantz et al. 2011). Our results also revealed the complex cross-talk between signal molecules and phytohormones during this plant-pathogen interaction. The concentrations of ABA were much lower in the infected $\mathrm{YN}$ than in the infected BX. ABA usually inhibits the expression of defense genes induced by JA (Anderson et al. 2004) and interacts antagonistically with the SA signaling pathway (Jiang et al. 2010; Meguro and Sato 2014; Xu et al. 2013). The higher ABA seemed to be related to the lower level of SA and lower resistance of BX to $F$. oxysporum $\mathrm{f}$. sp. cubense in our study. The lower concentration of IAA in the infected BX than in the infected YN, especially at the later infection time, might be related to the level change of SA and ABA signals (Park 2007). The continuous decline of CTK in infected BX compared with the infected YN during the infection process implied that cell division activity in BX was greatly
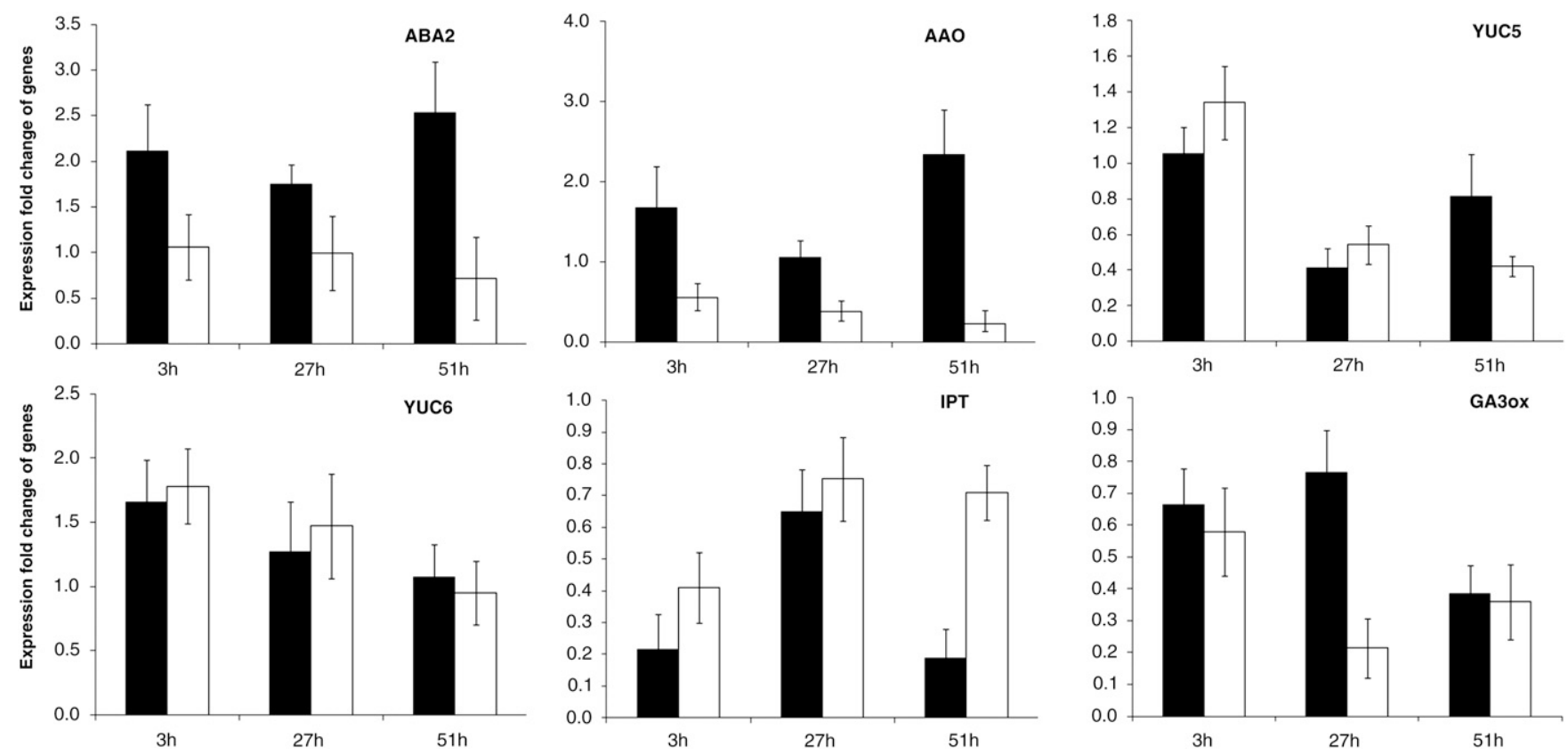

Fig. 6. Expression fold changes of genes committed to phytohormone biosynthesis during banana infection by Fusarium oxysporum f. sp. cubense strain TR4. Error bars represent standard error from six samples. The value was the ratio of the infected over the mock-inoculated banana plants. BaXi (filled column) and Musa yunnanensis (open column). ABA2 = xanthoxin dehydrogenase, $\mathrm{AAO}=$ abscisic aldehyde oxidase, $\mathrm{YUC}=$ flavin monooxygenase, $\mathrm{IPT}=$ isopentenyltransferase, and GA3ox $=2$-oxoglutarate-dependent dioxygenase.
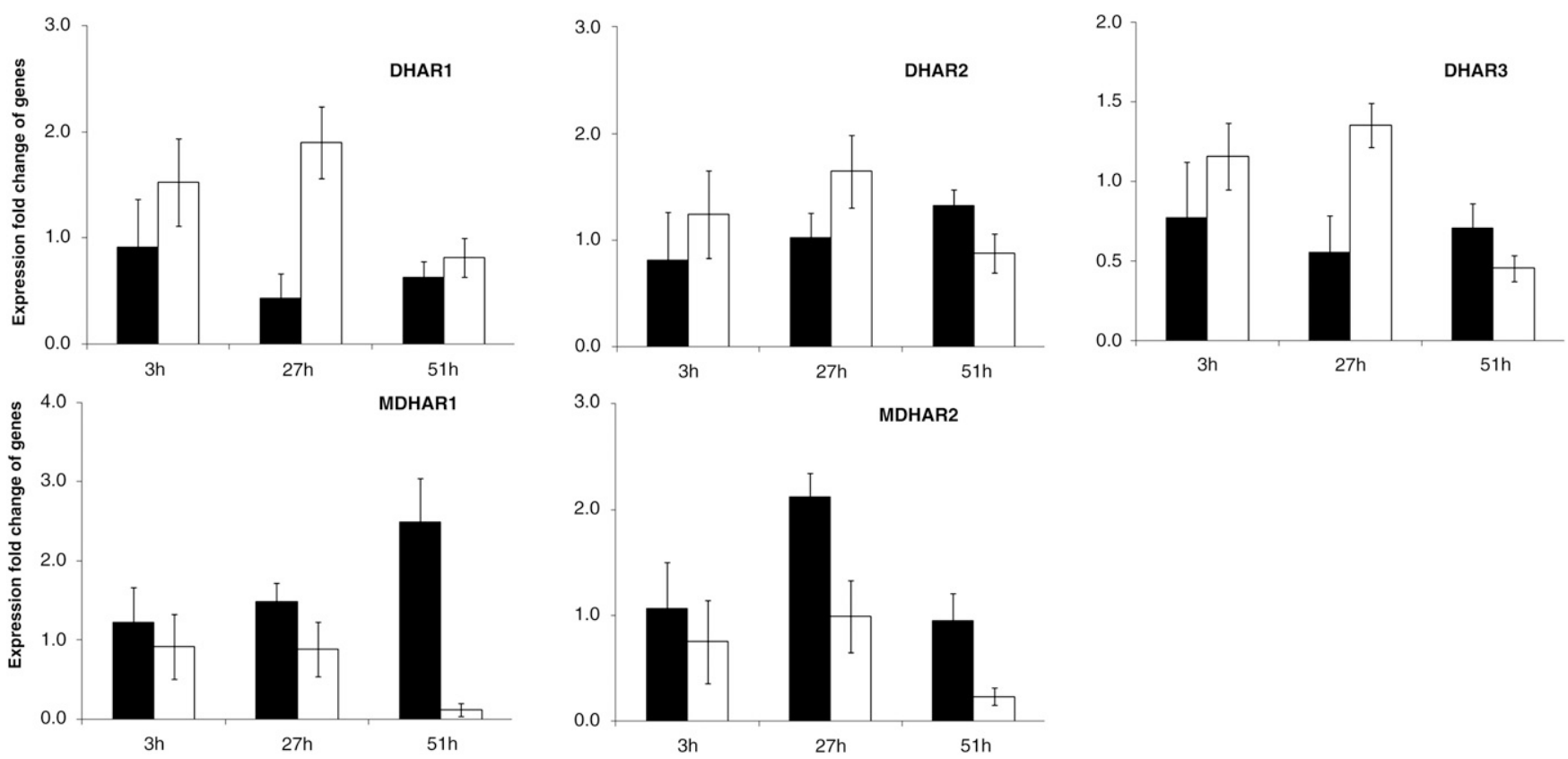

Fig. 7. Expression level changes of genes involved in ascorbic acid metabolism during banana infection by Fusarium oxysporum f. sp. cubense strain TR4. Error bars represent standard error from six samples. The value was the ratio of the infected over the mock-inoculated banana plants. BaXi (filled column) and Musa yunnanensis (open column). DHAR = glutathione S-transferase dehydroascorbate reductase and MDHAR = monodehydroascorbate reductase. 

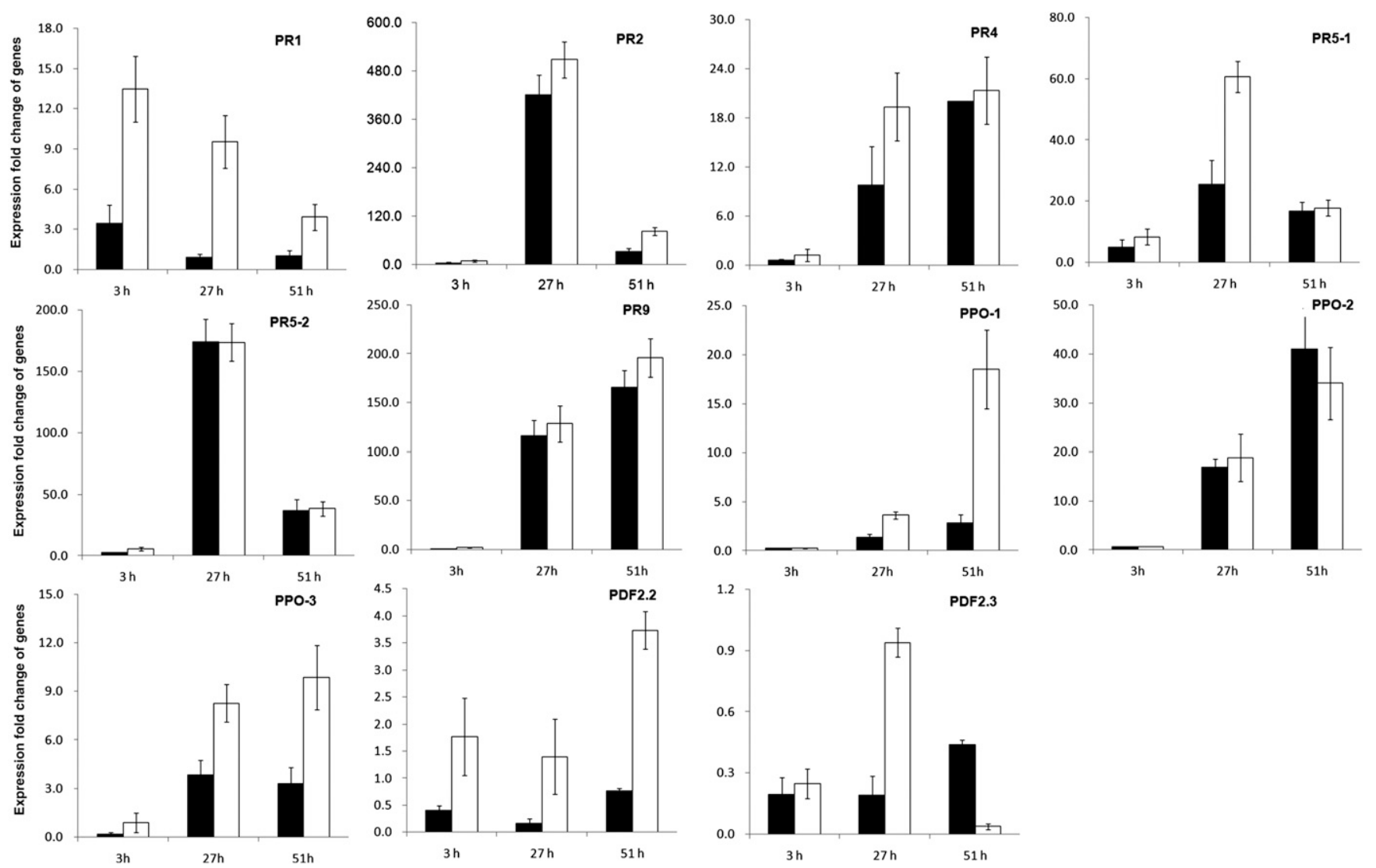

Fig. 8. Expression level changes of pathogenesis-related genes during banana infection by Fusarium oxysporum $\mathrm{f}$. sp. cubense strain TR4. Error bars represent standard error from six samples. The value was the ratio of the infected over the mock-inoculated banana plants. BaXi (filled column) and Musa yunnanensis (open column). PR1 = pathogenesisrelated gene 1, PR2 = endo-(1,4)- $\beta$-glucanase, PR4 = endochitinase, PR5 = thaumatin, PR9 = peroxidase, PPO = polyphenol oxidase, and PDF2.2 and $2.3=$ defensin-like

impaired due to the prolonged stress (Ghanem et al. 2008; Kudoyarova et al. 2007) and that the orchestrated CTK and SA signaling in response to plant pathogen attack would be disrupted (Choi et al. 2010; Sano et al. 1996). Although $\mathrm{GA}_{3}$ showed lower levels in the infected banana plants compared with the mock-inoculated plants, it still was higher in the infected BX than in the infected YN, which was coincident with the lower level of JA. As reported, JA was antagonistic with GA in regulating plant growth and resistance to pathogens through the regulation of DELLAs on JAZ1(Hou et al. 2010; Wild et al. 2012).

Our investigation into the expression level of genes indicates that the levels of some biosynthetic genes might determine the concentration of metabolites. In the infected $\mathrm{YN}$, the higher level of ICS resulted in a higher concentration of SA. The biosynthetic genes LOX1.1-3, ACO-1, AOS-1, AOS-3, AOS-4, AOC3-1, and 12-OPR-2 were more likely responsible for the JA biosynthesis in $F$. oxysporum f. sp. cubense-infected YN. Our study revealed direct relationships between the expression levels of $P R$ genes and the underlying induction signal molecules. For instance, the higher level of SA was consistent with the high expression levels of $P R 1, P R 2$, and $P R 5$ in the resistant YN, especially $27 \mathrm{~h}$ after inoculation, which may indicate how the resistant species responds to TR4 infection. The high level of JA (1.89-fold higher than in mock-inoculated plants) in YN might be intimately related to the expression of PR4 and PDF2.2.

The resistance response in the wild banana (M. yunnanensis) to $F$. oxysporum f. sp. cubense, especially strain TR4, involves higher levels of SA and CTK, lower levels of ABA, a higher concentration of phenolics, and an increase in $P R$ genes induced by SA. In contrast, the response of these compounds are opposite in the susceptible BX cultivar during the early stage of infection by TR4. These responses in BX might be explored to produce methods to control the pathogen, after more intense investigation in the future. Most importantly, understanding of the underlying response in the resistant banana species will allow for selective integration of these traits into commercially useful cultivars.

\section{Acknowledgments}

We thank W. Hu for his important suggestions and comments on data analysis and writing. Metabolomic analysis was supported by the Major Technology Project of Hainan (ZDZX2013023-1). The measurement of hormones, gene cloning, and verification were supported by the National Nonprofit Institute Research Grant ITBB2015ZY02 and were also funded by Young Science and Technology Talent Project of Hainan Science and Technology Association (HAST201630).

\section{Literature Cited}

Adie, B. A., Perez-Perez, J., Perez-Perez, M. M., Godoy, M., Sanchez-Serrano, J. J., Schmelz, E. A., and Solano, R. 2007. ABA is an essential signal for plant resistance to pathogens affecting JA biosynthesis and the activation of defenses in Arabidopsis. Plant Cell 19:1665-1681.

Alvarez, M. E. 2000. Salicylic acid in the machinery of hypersensitive cell death and disease resistance. Plant Mol. Biol. 44:429-442.

Anderson, J. P., Badruzsaufari, E., Schenk, P. M., Manners, J. M., Desmond, O. J., Ehlert, C., Maclean, D. J., Ebert, P. R., and Kazan, K. 2004. Antagonistic interaction between abscisic acid and jasmonate-ethylene signaling pathways modulates defense gene expression and disease resistance in Arabidopsis. Plant Cell 16:3460-3479.

Bao, G., Zhuo, C., Qian, C., Xiao, T., Guo, Z., and Lu, S. 2016. Co-expression of NCED and ALO improves vitamin $C$ level and tolerance to drought and chilling in transgenic tobacco and stylo plants. Plant Biotechnol. J. 14:206-214.

Barding, G. A., Jr., Beni, S., Fukao, T., Bailey-Serres, J., and Larive, C. K. 2013 Comparison of GC-MS and NMR for metabolite profiling of rice subjected to submergence stress. J. Proteome Res. 12:898-909.

Beckman, C. H. 1990. Host responses to the pathogen. Pages 93-105 in Fusarium Wilt of Banana. R. C. Ploetz, ed. American Phytopathological Society, St. Paul, MN.

Bosch, M., Berger, S., Schaller, A., and Stintzi, A. 2014. Jasmonate-dependent induction of polyphenol oxidase activity in tomato foliage is important for defense against Spodoptera exigua but not against Manduca sexta. BMC Plant Biol. 14:257.

Chen, H. B., Feng, Q. R., Xu, C. X., Huo, R. X., Li, J. G., and Wang, Z. H. 2006 Screening of banana clones for resistance to Fusarium wilt (Fusarium oxysporum f. sp. cubense). Hua Nan Nong Ye Da Xue Xue Bao 27:9-12.

Choi, J., Huh, S. U., Kojima, M., Sakakibara, H., Paek, K. H., and Hwang, I. 2010 The cytokinin-activated transcription factor ARR2 promotes plant immunity 
via TGA3/NPR1-dependent salicylic acid signaling in Arabidopsis. Dev. Cell 19:284-295.

De Ascensao, A. R. D. C. F., and Dubery, I. A. 2000. Panama disease: Cell wall reinforcement in banana roots in response to elicitors from Fusarium oxysporum f. sp. cubense race four. Phytopathology 90:1173-1180.

de Ascensao, A. R. F. D. C., and Dubery, I. A. 2003. Soluble and wall-bound phenolics and phenolic polymers in Musa acuminata roots exposed to elicitors from Fusarium oxysporum f. sp. cubense. Phytochemistry 63:679-686.

García-Sánchez, M., Garrido, I., Casimiro Ide, J., Casero, P. J., Espinosa, F., Garcia-Romera, I., and Aranda, E. 2012. Defence response of tomato seedlings to oxidative stress induced by phenolic compounds from dry olive mill residue. Chemosphere 89:708-716.

Ghanem, M. E., Albacete, A., Martinez-Andujar, C., Acosta, M., Romero-Aranda, R., Dodd, I. C., Lutts, S., and Perez-Alfocea, F. 2008. Hormonal changes during salinity-induced leaf senescence in tomato (Solanum lycopersicum L.). J. Exp. Bot. 59:3039-3050.

Glazebrook, J. 2005. Contrasting mechanisms of defense against biotrophic and necrotrophic pathogens. Annu. Rev. Phytopathol. 43:205-227.

Ha, S., Vankova, R., Yamaguchi-Shinozaki, K., Shinozaki, K., and Tran, L. S. 2012. Cytokinins: Metabolism and function in plant adaptation to environmental stresses. Trends Plant Sci. 17:172-179.

Häkkinen, M., and Wang, H. 2007. New species and variety of Musa (Musaceae) from Yunnan, China. Novon J. Bot. Nomencl. 17:440-446. doi:10.3417/10553177(2007)17[440:NSAVOM]2.0.CO;2

Herbert, J. A., and Marx, D. 1990. Short-term control of Panama disease of bananas in South Africa. Phytophylactica 22:339-340.

Hou, X., Lee, L. Y., Xia, K., Yan, Y., and Yu, H. 2010. DELLAs modulate jasmonate signaling via competitive binding to JAZs. Dev. Cell 19:884-894.

Huang, B. Z., Xu, L. B., Yang, H., Tang, X. L., Wei, Y. R., Qiu, J. S., and Li, G. Q 2005. Preliminary results of field evaluation of banana germplasm resistant to Fusarium wilt disease. Guangdong Agric. Sci. 6:9-10.

Jiang, C. J., Shimono, M., Sugano, S., Kojima, M., Yazawa, K., Yoshida, R., Inoue, H., Hayashi, N., Sakakibara, H., and Takatsuji, H. 2010. Abscisic acid interacts antagonistically with salicylic acid signaling pathway in riceMagnaporthe grisea interaction. Mol. Plant-Microbe Interact. 23:791-798.

Joshi, J. R., Burdman, S., Lipsky, A., and Yedidia, I. 2015. Effects of plant antimicrobial phenolic compounds on virulence of the genus Pectobacterium. Res. Microbiol. 166:535-545.

Kovacs, I., Durner, J., and Lindermayr, C. 2015. Crosstalk between nitric oxide and glutathione is required for NONEXPRESSOR OF PATHOGENESISRELATED GENES 1 (NPR1)-dependent defense signaling in Arabidopsis thaliana. New Phytol. 208:860-872.

Kudoyarova, G. R., Vysotskaya, L. B., Cherkozyanova, A., and Dodd, I. C. 2007. Effect of partial rootzone drying on the concentration of zeatin-type cytokinins in tomato (Solanum lycopersicum L.) xylem sap and leaves. J. Exp. Bot. 58:161-168.

Li, C., Shao, J., Wang, Y., Li, W., Guo, D., Yan, B., Xia, Y., and Peng, M. 2013a. Analysis of banana transcriptome and global gene expression profiles in banana roots in response to infection by race 1 and tropical race 4 of Fusarium oxysporum f. sp. cubense. BMC Genomics 14:851.

Li, C.-Y., Deng, G.-M., Yang, J., Viljoen, A., Jin, Y., Kuang, R.-B., Zuo, C.-W., Lv, Z.-C., Yang, Q.-S., Sheng, O., Wei, Y.-R., Hu, C.-H., Dong, T., and Yi, G.-J. 2012. Transcriptome profiling of resistant and susceptible Cavendish banana roots following inoculation with Fusarium oxysporum f. sp. cubense tropical race 4. BMC Genomics 13:374.

Li, W. B., Li, C. Q., Sun, J. B., and Peng, M. 2015a. Expression analysis of MaTLP and MaBGLU in banana germplasm with different resistant infected by Fusarium oxysporum f. sp. cubense. Mol. Plant Breed. 13:310-316.

Li, W. B., Liu, Y. F., Zeng, S. H., Xiao, G., Wang, G., Wang, Y., Peng, M., and Huang, H. W. 2015b. Gene expression profiling of development and anthocyanin accumulation in kiwifruit (Actinidia chinensis) based on transcriptome sequencing. PLoS One 10:e0136439.

Li, W. M., Dita, M., Wu, W., Hu, G. B., Xie, J. H., and Ge, X. J. 2015c. Resistance sources to Fusarium oxysporum f. sp. cubense tropical race 4 in banana wild relatives. Plant Pathol. 64:1061-1067.

Li, X., Bai, T., Li, Y., Ruan, X., and Li, H. 2013b. Proteomic analysis of Fusarium oxysporum $\mathrm{f}$. sp. cubense tropical race 4-inoculated response to Fusarium wilts in the banana root cells. Proteome Sci. 11:41.

Liu, X. Y., Zhou, D. B., Gao, Z. F., Tan, X., Zhao, Y. K., Chen, B., Huang, X., and Zhang, X. Y. 2012. Selection of soil disinfection disinfectant against banana vascular wilt. Guangdong Agric. Sci. 18:68-70.

Livak, K. J., and Schmittgen, T. D. 2001. Analysis of relative gene expression data using real-time quantitative PCR and the $2^{-\Delta \Delta \mathrm{Ct}}$ method. Methods 25:402-408.

Lorang, J. M., Tuori, R. P., Martinez, J. P., Sawyer, T. L., Redman, R. S., Rollins, J. A., Wolpert, T. J., Johnson, K. B., Rodriguez, R. J., Dickman, M. B., and Ciuffetti, L. M. 2001. Green fluorescent protein is lighting up fungal biology. Appl. Environ. Microbiol. 67:1987-1994.

Mahdavi, F., Sariah, M., and Maziah, M. 2012. Expression of rice thaumatin-like protein gene in transgenic banana plants enhances resistance to fusarium wilt. Appl. Biochem. Biotechnol. 166:1008-1019.

Mandal, S., Mallick, N., and Mitra, A. 2009. Salicylic acid-induced resistance to Fusarium oxysporum f. sp. lycopersici in tomato. Plant Physiol. Biochem. 47:642-649.

Meguro, A., and Sato, Y. 2014. Salicylic acid antagonizes abscisic acid inhibition of shoot growth and cell cycle progression in rice. Sci. Rep. 4:4555.
Nel, B., Steinberg, C., Labuschagne, N., and Viljoen, A. 2007. Evaluation of fungicides and sterilants for potential application in the management of Fusarium wilt of banana. Crop Prot. 26:697-705

Novak, J., Pavlu, J., Novak, O., Nozkova-Hlavackova, V., Spundova, M., Hlavinka, J., Koukalova, S., Skalak, J., Cerny, M., and Brzobohaty, B. 2013 High cytokinin levels induce a hypersensitive-like response in tobacco. Ann. Bot. (Lond.) 112:41-55.

Park, C. M. 2007. Auxin homeostasis in plant stress adaptation response. Plant Signal. Behav. 2:306-307.

Pérez-Jiménez, J., and Saura-Calixto, F. 2005. Literature data may underestimate the actual antioxidant capacity of cereals. J. Agric. Food Chem. 53:5036-5040.

Ploetz, R. C. 2006. Fusarium wilt of banana is caused by several pathogens referred to as Fusarium oxysporum f. sp. cubense. Phytopathology 96:653-656.

Ploetz, R. C. 2015. Fusarium wilt of banana. Phytopathology 105:1512-1521.

Radhajeyalakshmi, R., Xia, Y. J., and Shah, D. 2014. Evidence of salicylic acid regulatory mechanisms of disease resistance against banana vascular wilt Fusarium oxysporium f. sp. cubense in Arabidipsis thaliana. Afr. J. Biotechnol. 13:3030-3035.

Robert-Seilaniantz, A., Grant, M., and Jones, J. D. 2011. Hormone crosstalk in plant disease and defense: More than just jasmonate-salicylate antagonism. Annu. Rev. Phytopathol. 49:317-343.

Ruan, M. B., Li, W. B., Yu, X., and Peng, M. 2011. Rapid isolation of high-quality RNA from high phenol-, polysaccharide plants. Chin. J. Trop. Crops 32:1704-1707.

Sano, H., Seo, S., Koizumi, N., Niki, T., Iwamura, H., and Ohashi, Y. 1996. Regulation by cytokinins of endogenous levels of jasmonic and salicylic acids in mechanically wounded tobacco plants. Plant Cell Physiol. 37:762-769.

Shah, J., Kachroo, P., Nandi, A., and Klessig, D. F. 2001. A recessive mutation in the Arabidopsis SSI2 gene confers SA- and NPR1-independent expression of PR genes and resistance against bacterial and oomycete pathogens. Plant J. 25:563-574

Singleton, V. L., and Rossi, J. A., Jr. 1965. Colorimetry of total phenolics with phosphomolybdic-phosphotungstic acid reagents. Am. J. Enol. Vitic. 16:144-158

Sinha, R., Kumar, D., Datta, R., Hazra, S., Bhattacharyya, D., Mazumdar, A. B., Mukhopadhyay, R., Sultana, A., and Chattopadhyay, S. 2015. Integrated transcriptomic and proteomic analysis of Arabidopsis thaliana exposed to glutathione unravels its role in plant defense. Plant Cell Tissue Organ Cult. 120:975-988.

Su, H.-J., Hwang, S.-C., and Ko, W.-H. 1986. Fusarial wilt of Cavendish bananas in Taiwan. Plant Dis. 70:814-818.

Thomma, B. P., Eggermont, K., Penninckx, I. A., Mauch-Mani, B., Vogelsang, R., Cammue, B. P., and Broekaert, W. F. 1998. Separate jasmonate-dependent and salicylate-dependent defense-response pathways in Arabidopsis are essential for resistance to distinct microbial pathogens. Proc. Natl. Acad. Sci. USA 95: 15107-15111.

van den Berg, N., Berger, D. K., Hein, I., Birch, P. R. J., Wingfield, M. J., and Viljoen, A. 2007. Tolerance in banana to Fusarium wilt is associated with early up-regulation of cell wall-strengthening genes in the roots. Mol. Plant Pathol. 8:333-341. doi:10.1111/j.1364-3703.2007.00389.x

Wang, B. B., Yuang, J., Zhang, J., Shen, Z. Z., Zhang, M. X., Li, R., Ruan, Y. Z., and Shen, Q. R. 2013. Effects of novel bioorganic fertilizer produced by Bacillus amyloliquefaciens W19 on antagonism of Fusarium wilt of banana Biol. Fertil. Soils 49:435-446.

Wang, Z., Jia, C., Li, J., Huang, S., Xu, B., and Jin, Z. 2015. Activation of salicylic acid metabolism and signal transduction can enhance resistance to Fusarium wilt in banana (Musa acuminata L. AAA group, cv. Cavendish). Funct. Integr. Genomics 15:47-62.

Wang, Z., Zhang, J., Jia, C., Liu, J., Li, Y., Yin, X., Xu, B., and Jin, Z. 2012. De novo characterization of the banana root transcriptome and analysis of gene expression under Fusarium oxysporum f. sp. cubense tropical race 4 infection. BMC Genomics 13:650.

Wild, M., Daviere, J. M., Cheminant, S., Regnault, T., Baumberger, N., Heintz, D. Baltz, R., Genschik, P., and Achard, P. 2012. The Arabidopsis DELLA RGALIKE3 is a direct target of MYC2 and modulated jasmonate signaling responses. Plant Cell 24:3307-3319.

Xiao, R. F., Zhu, Y. J., Li, Y. D., Huang, S. F., and Liu, B. 2009. Green fluorescent protein gene transformation on Fusarium oxysporum $\mathrm{f}$. sp. niveum strain, FOV135. Fujian J. Agric. Sci. 24:521-524.

Xie, X. Z., Xue, Y. J., Zhou, J. J., Zhang, B., Chang, H., and Takano, M. 2011. Phytochromes regulate $\mathrm{SA}$ and JA signaling pathways in rice and are required for developmentally controlled resistance to Magnaporthe grisea. Mol. Plant 4:688-696.

Xin, K., Zhao, N., Deng, X. K., Dong, C. M., Li, R., and Ruan, Y. Z. 2014. Effects of rice rotation incorporated with organic materials on suppression of banana Fusarium wilt disease. Plant Prot. 40:36-41.

Xu, J., Audenaert, K., Hofte, M., and De Vleesschauwer, D. 2013. Abscisic acid promotes susceptibility to the rice leaf blight pathogen Xanthomonas oryzae pv. oryzae by suppressing salicylic acid-mediated defenses. PLoS One 8:e67413.

Yang, W. M., Liu, X. Q., Wang, C. T., and Sheng, R. L. 2005. Endogenous hormones content determination by chromatography of rice seedlings. J. Wuhan Univ. Sci. Eng. 18:61-64.

Zhang, N., Wu, K., He, X., Li, S. Q., Zhang, Z. H., Shen, B., Yang, X. M., Zhang, R. F., Huang, Q. W., and Shen, Q. R. 2011. A new bioorganic fertilizer can effectively control banana wilt by strong colonization with Bacillus subtilis N11. Plant Soil 344:87-97. 